\title{
Exploring Teaching Reform of Engineering Drawing with Craftsmanship Spirit
}

\author{
SUN Yu \\ College of Engineering \\ Ocean University of China \\ Qingdao, P.R.China \\ cqdoucsuny@163.com
}

\author{
YIN Xing \\ College of Engineering \\ Ocean University of China \\ Qingdao, P.R.China \\ yinxing1995@hotmail.com
}

\begin{abstract}
With the development of technology, the traditional teaching methods of Engineering Drawing cannot adapt to the requirements of the times. To obtain satisfactory teaching effectiveness and meet the requirements of the construction industry in the new period, we reformed traditional teaching methods under the guidance of Craftsmanship Spirit uniquely. This paper analyzed the existing problems in the current and summarized a set of effective teaching methods which can help students form rigorous working style and enhance their drawing ability. Practice shows that these methods achieve satisfactory teaching results. The combination of Craftsmanship Spirit and teaching reform also has certain reference significance to other fields.
\end{abstract}

Keywords-Craftsmanship spirit; Engineering Drawing; Teaching reform; Civil Engineering

\section{INTRODUCTION}

In this year's Government Work Report, Premier LI Keqiang mentioned the term "Craftsmanship spirit", and it drew much public attention. Craftsmanship spirit refers to the dedication craftsmen give to their work in order to make it as perfect as possible, and the essence of craftsmanship spirit is careful and rigorous attitude toward work. [1] In the modern society in China, this excellent quality has an important social value.

The course of Descriptive Geometry and Civil Engineering Drawing is a basic specialty course with strong theoretical and professional practicality for the major of Civil Engineering. According to Ministry of Housing and Urban-Rural Development of the People's Republic of China(MOHURD), the lowest requirement for the civil engineering graduates is the ability to read common engineering drawing. However, for various reasons, such as insufficient class time, inconsistent with follow-up courses, overdependence on software, etc. students are inferior in their graphics interpreting ability, plotting ability and interspace imagination ability, which result in low-qualities building structure construction drawings.

During the teaching reform of the Engineering Drawing course, we guide teaching with craftsmanship spirit and summarizes a set of effective practical teaching methods which can help students form rigorous working style and favorable study attitude.

\section{ANAlyze The PRoblems EXISTING IN THE CURRENT TEACHING MODEL}

\section{A. Insufficient class time}

The course of Descriptive Geometry and Civil Engineering Drawing meets four hours per week, with students receiving four credits for their efforts. Thus, insufficient class time is one of the prominent issues of teaching at present. Due to the limitation of time and space, students cannot master the Unified standard for building drawings (GB/T 50001), which has an extremely negative impact on the enhancement of the engineering drawing ability. Since drawing in class spends much time of students and teachers, it could not afford to do a lot of exercises in classes. Thus, teachers hardly correct mistakes of students' drawings and students often don't realize their drawing mistakes. It adds up to a vicious cycle.

\section{B. Inconsistent with follow-up courses}

Since follow-up courses do not ask students make drawings completely meet the requirements set out in Drawing Standards and do not judge students' assignments with types of line, line widths and dimension, such as Materials of Mechanics, Structural Mechanics, Basic Principles of Concrete Structures and Basic Principles of Steel Structures, etc. These causing students' lack comprehensive and systematic drawing training.

Many students disregard the importance of engineering drawing without being conscious that this course is a specialty characteristic of practice. Besides, some teachers also blindly yield to students and ignore that a qualified civil engineer needs to translate the ideas from mechanics, calculations and structural concepts in to engineering drawing which are used in civil engineering construction.

\section{Overdependence on software}

With the development of technology, board-drafting skills are rapidly being replaced by computer-aided drafting (CAD) and students need to master various civil engineering calculation and design software, such as AutoCAD, PKPM, TSSD, Tarch and Revit. However, teachers mainly focus on basic operations, shortcut commands and operative skill, ignoring the requirement which sets out in Drawing Standards. Students do not have a sense of the limitations of software and depend on functions that software generates all the drawings. 
They totally overlook the accuracy and normalization of drawings.

\section{TEACHING REFORM UNDER THE GUIDANCE OF CRAFTSMANSHIP SPIRIT}

Engineering Drawing is concerned with the expression of technical ideas and it is the communication method used in all branches of engineering. [2] For this reason, engineering drawing is called the language of engineering. Engineering Drawing is not only an integral part of design documents, but also an important guidance of construction. It can seriously threaten human being's lives and properties when there are ambiguity, mistakes and omission in design drawing.

Making prefect engineering drawing requires the craftsmanship spirit, in other words, the spirit to pursue the best, or rather, perfection. Many students think of draftsmen as no more than skilled workers who can only repetitively complete some operation. But there is more to them than that. Craftsmanship Spirit requests students master descriptive geometry knowledge, engineering drawing ability and the Drawing Standards of buildings.

The author made following attempts in reforming teaching method under the guidance of craftsmanship spirit and good result has been obtained.

\section{A. Promote the education of craftsmanship spirit}

Engineering is rather important to the developemnt of county, but there is a lack of responsibility and patience in modern world. As the first specialized course for freshmen of civil engineering, this course need to help students develop personal qualities and form rigorous working style.

We believe that these qualities should be equipped with the prospective civil engineers: rigorous scholarship, responsibility, patience, creative ability, the ability of renewing knowledge and interpersional skills. These qualities could be summarized to Craftsman Spirit. We use a variety of methods to nurture students' craftsman spirit and change students' "just so-so" attitude.

\section{B. Improve drawings' quality of detail}

The art of making a normative drawing requires extreme attention to detail and pursuit of perfection. And this is exactly what the craftsmanship spirit requested.

Take the Kansa City Hyatt Regency Walkways Collapse as an example.

On July 17th, 1981, two suspended walkways within the atrium area of the Hyatt Regency Hotel in Kansas City, Mo., collapsed, leaving 113 people dead and 186 injured. In terms of loss of life and injures, this was the most devastating structural collapse ever to take place in the United States. [3]

National Bureau of Standards(NBS) was asked to determine the most probable cause. After NBS consulted documents such as drawing, specifications, inspection reports, test reports, and construction logs, as well as photographs and videotape, they gained information about the walkways as originally approved for construction and as modified during the construction process. NBS also conducted extensive laboratory tests on Bureau-fabricated mockups of parts of the walkways.

Based on field, laboratory, and analytical investigations, NBS found that the plans for the walkways approved originally for constructions were correct. However, during construction, there were mistakes on shop drawings. Although contractor, structural engineer and architect reviewed these shop drawings, they were so careless that the mistakes were ignored completely.

Finally, engineer of record and project engineer had their professional engineering licenses revoked; Construction Company also lost its certificate of authority.

In practice, we introduce these construction work accidents which caused by mistakes of engineering drawing, and guide students to read Investigation of the Kansas City Hyatt Regency Walkways Collapse, after that, students pay much more attention to detail of engineering drawing and their drawing abilities have been enhanced.

Besides, a drawing made in the P.R.China must meet the requirements set out in the Unified standard for building drawings (GB/T 50001-2010). We ask students to read this Drawing Standard carefully and familiar with it as far as possible, especially to the requirement of line widths, line style, and letter and dimensioning.

\section{Combine course with engineering practice}

Practice in drawing should focus on practical and combine with actual engineering, which develops students' manipulative ability and space imagination ability. Besides, these practices also help students with developing a good sense of accuracy of observation and proportion, which is rather useful in their work.

Different from natural sciences, engineering promotes the theory and practice; this is also what the craftsmanship spirit requested. Since civil engineering students need to guide the construction after graduation, some practical experience is required for students to put the reasonable engineering intention that the engineering drawings expressed into practice. To help students get practical experience of engineering, we encourage students solving problems through sketching and making axonometric drawings. We also guide students to consciously observe objects and draw sketches, which help students with strengthening the concept of space.

Take the University of Illinois Urbana-Champaign as an example, under the UIUC's heading "Methods of Instruction" appears the statement: "In drawing, besides copying the exercises given in the text books, students will be required to make plots of actual surveys, plans and elevations of buildings and machines from actual measurement, and will be expected from time to time, to produce original designs of proposed structures." [4] Since civil engineering is a very practical subject, combining descriptive geometry theory with engineering practice in the exercises and examples can train the ability of solving engineering problems.

Moreover, some students cannot see the wood for the trees, they can deal with geometrical figures' three views and sectional views, but when it comes to the whole buildings, they 
cannot handle them. From this point of view, we ask students accomplish the whole buildings' shop drawings (including plans, elevations, sections, axonometric drawing and details) in the form of sketches cooperatively, which provide students with an integral and comprehensive opportunity.

\section{Help students recognize the limitations of software}

The craftsmanship spirit impels craftsmen continuously to study technique, neithor they only repetitively complete some operation, nor they rely on tools completely. However, from the feedback of employer, many students are relying too much on uasge of software and laking of basic drawing skills. More seriously, students blindly accept the drawing which generated by software without discrimination.

It is clear to us that computer software is just a tool and it can not substitute human being's creativity. Thus, teachers should guide students through recognizing the limitations of software. If not, we are training the "slaves" of computer software rather than civil engineers.

To help students break their trust of computer software, we distribute them with engineering drawings which are automatically generated by software. They are required to find errors and compare with model. These exercises both develop students' ability of reading drawings and help them recognize the limitations of software. Besides, students understand that they cannot rely on computer technology completely, computer software is just a tool and cannot substitutes creativity of human beings.

What's more, to impart meticulous and rigorous working attitude to students, we also show students excellent engineering drawings that made by Class-A design institutes, which help students with recognizing their individual limitations.

\section{E. Value traditional manual drawing}

Though CAD is replacing manual drawing because of its speed and economy, manual drawing is still an important method of communication. As one of the quickest ways to express ideas, manual drawing help engineers to explain thoughts and concepts to other people. In practice, students blindly trusting the drawings which generated by software without judgment it's accuracy and normalization. They blindly promote efficience and ignore the basic theory of descriptive geometry, they also have no patience to make drawing by pencils and T-squares. However, the ability of manual drawing making is necessary for anyone who works in any of the field of civil engineering, and it is essential for those who plan to become a civil engineer. It means teachers should demonstrate how to make freehand drawing, instead of completely rely on computer-aided instruction(CAI). Meanwhile, students should be as patient as craftsmen, rather than promote efficience blindly.

Traditional manual drawing is the foundation of engineering drawing and it plays an irreplaceable role in improving the ability of spatial imagination and the ability of expressing their design intention. As for computer-aided drawing(CAD), it is still a kind of tool and it can not take place design sinking and image thinking. [5][6] According to James M Leake's research, manual drawing is more effective than 3D modeling of computer in the aspect of improving students' ability of spatial visualization ability. [4] It is hard for students to use computers to make engineering drawing accurately and correct engineering drawings skillfully without rigorous manual drawing training.

For such reason, we spend much time on the training of manual drawing training, we also propose definite demand for abilities and skills of manual drawing. Students are required to draw parallel lines and perpendicular freehand. Meanwhile, students are also taught to draw scenograph and axonometric drawing freehand. To make sure that students acutually master the basic abilities and skills of engineering drawing, TAs also guide students through assignments after class.

What's more, some contents of Descriptive Geometry and Civil Engineering Drawing are deleted to adapt to development of technology. For instance, students spent much time on making drawing accurately by various drawing implements like T-square, set-square and compass in previous. However, it is clear that they cannot dimension as accurately as computer no matter how careful they were, and the engineering drawings and 3D models with accurate dimension can be drawn by computer software later. Thus, teachers emphasize the expression of design intent and the requirements set out in Drawing Standards, like line widths, line style and dimensioning, rather than accurate dimension. These methods fully reflect that the essential mission of engineering drawing is to serve engineering structure's design and construction.

\section{F. Build network teaching system}

With the rapit development of multimedia technology and the improvement of teaching conditions, computer-aided instruction (CAI) has become the essential means of engineering drawing's teaching. Compared with CAI courseware, traditional teaching method can only use limited number of blackboards and models. However, because of insufficient class time and the using of CAI courseware, students are likely unable to keep up with course scheduling.

In order to improve the quality of taching effectively, we adapt to the development of internet and build network teaching system with the help of instant messaging software like QQ and WeChat. Teachers and TAs set up QQ group and WeChat group to help students with the difficulties of this course. Moreover, students are encouraged to discuss and share with experience each other between classmates, and teachers mainly act as the dominant roles to guide and inspire students. Teachers also share students with frontier and development in civil engineering, which helps students as freshmen with understanding the coverage of major.

\section{G. Arouse more interest and motivation in students}

It is inevitable to stay up late during the study of engineering drawing, making drawings and modifying drawings. Thus, patience and enterprise is particularly important. During the teaching process, teachers should try flexible and diverse forms of teaching to exert students' 
creation. Only in this way, can students improve the learning enthusiasm and stimulate their interest in study. [7]

Compared with the traditional drawing assignments, outdoor study can definitely arouse more interest and motivation in students. We divide students into groups and guide them investigate real constructions. After that, we ask them to discuss the structural composition of buildings and paint out each layer of plan, elevation and section as their assignments. With this method, students equip with perceptual knowledge about buildings and they are interested in civil engineering.

\section{CONCLUSION}

Descriptive Geometry and Civil Engineering Drawing is an important professional foundation course, and the important position determines the seriousness of engineering drawings. It means that engineers must meet the meet the requirements set out in Drawing Standards and reading drawing carefully. Any mistakes and misunderstanding can result in substantial consequences.

Therefore, it is necessary to reform teaching model under the guidance of craftsmanship spirit. Craftsmanship spirit can help students cultivate the good habit of drawing. It should be pointed out that the craftsmanship spirt is not only necessary for the engineering drawing, but should be advocated in students' profession of civil engineers. If this spirit can be embodied by every student in their attitudes toward his profession and related ethics, our society would achieve a lot more.

\section{REFERENCES}

[1] XIAO Qunzhong and LIU Yongcun, "Craftsmanship spirit and Its Contemporary Value" Social Sciences in Hunan, vol. 6, pp 6-10, 2015. (references) (In Chinese)

[2] CAO Bang-qing, "Civil engineering drawing course quality of teaching guarantee system construction and practice” Journal of Nanyang Normal University, vol. 9, pp. 110-113, 2010

[3] U.S DEPARTMENT OF COMMERCE and NATIONAL BUREAU OF STANDARDS, Investigation of the Kansas City Hyatt Regency Walkways Collapse, Washington, DC, May 1982. (references)

[4] FENG Juan, "Analysis on Engineering Graphics Education in U.S. Universities” Journal of Graphics, Beijing, vol. 3, pp. 139-144, 2008.

[5] Wang H and Pan C, "Teaching reform of Engineering Graphics - on the relationship between hand drawing and computer drawing". ICIBET, Vol. 13, pp 995-998, 2013.

[6] Yeh-Liang Hsu and Chin-Yu Yo, "Problem-solving approach for the fundamental hands-on practice courses in mechanical engineering education” Journal of the Chinese Society of Mechanical Engineers, Taiwan, vol. 24. pp.517-524, October 2003.

[7] HOU Wei, ZHOU Xue-feng, QI Feng and CHEN Xiang, "Teaching reform of civil engineering drawing course based on application ability training" Journal of Architectural Education in Institutions of Higher Learning, Vol. 19(1). pp 70-73, 2010. 